\title{
The Impact of Age Stereotypes on Well-being: Strategies of Selection, Optimization, and Compensation as Mediator and Regulatory Focus as Moderator: Findings from a Cross-Sectional and a Longitudinal Study
}

\author{
Martin Söllner $^{1} \cdot$ Mirjam Dürnberger $^{1} \cdot J^{\prime}$ Johannes Keller ${ }^{2} \cdot$ Arnd Florack $^{1}$ (D)
}

Accepted: 27 May 2021 / Published online: 7 June 2021

(C) The Author(s) 2021

\begin{abstract}
In a cross-sectional (Study 1) and a longitudinal study (Study 2), the authors examined whether the association between age stereotypes and well-being is mediated by self-regulatory engagement in goal pursuit. In Study $1(N=666)$, engagement in self-regulatory strategies of selection (e.g., selecting appropriate goals), optimization (e.g., acquiring resources for goal achievement), and compensation (e.g., searching for help) were assessed as potential mediators and, concurrently, regulatory focus was explored as a moderator of the association of age stereotypes and well-being. The results demonstrated consistent positive associations of positive age stereotypes and different kinds of well-being. These associations were partially mediated by optimization, but not by selection or compensation. Furthermore, the relationships between positive age stereotypes and well-being were attenuated for promotion-focused individuals. In Study $2(N=2325)$, we measured age stereotypes at baseline and several well-being measures at baseline as well as 6 and 9 years later. Age stereotypes at baseline predicted well-being at the later measurement times. Also, the associations between age stereotypes and different aspects of well-being were mediated by self-regulatory engagement in selection, optimization, and compensation.
\end{abstract}

Keywords Well-being · Age stereotypes $\cdot$ Self-regulation $\cdot$ Adaptation

The ideas and expectations individuals have about ageing vary widely (Hummert, 1999; Hummert et al., 1994). For some, ageing is associated with loneliness and declining quality of life, while others value the emotional stability, friendliness, and life experience of older adults. Individuals acquire such age stereotypes throughout their lives, but unlike other types of stereotypical attributes associated with social groups, these stereotypes affect all individuals when they reach an older age. Researchers therefore conclude that age

Arnd Florack

arnd.florack@univie.ac.at

1 Faculty of Psychology, Department of Occupational, Economic, and Social Psychology, University of Vienna, Vienna, Austria

2 Faculty of Engineering, Computer Science, and Psychology, Ulm University, Ulm, Germany 
stereotypes influence not only the perception of other people, but also the self-perception of older adults, and beyond that, their motivation, behavior, and well-being (Levy, 2009). In line with this premise, various studies revealed a relationship between age stereotypes and intentions to change behavior (Söllner \& Florack, 2019a, 2019b), will to live (Levy, Asman, \& Dror, 2000), and well-being (Kornadt \& Rothermund, 2011). However, little is known about how age stereotypes are related to specific strategies of goal pursuit and regulatory engagement that contribute to successful ageing, and whether such strategies mediate the relation between age stereotypes and well-being.

The Selection, Optimization and Compensation (SOC) theory (Baltes \& Baltes, 1990; Freund \& Baltes, 1998) proposes three strategies of regulatory engagement (SOC strategies) that contribute to maintaining well-being throughout the entire life-span: (a) selecting and prioritizing goals (selection), (b) acquiring means and energy for goal achievement (optimization), and (c) counteracting possible losses through increased effort or seeking help (compensation). In the present studies, we examined whether these strategies are related to age stereotypes and whether they mediate the relationship between age stereotypes and well-being. Furthermore, we investigated the regulatory focus of individuals as a potential moderator of the association of age stereotypes with well-being. The present research contributes to the understanding of age stereotypes as a self-relevant determinant of experience and behavior and shows how age stereotypes can be linked to the literature on goal pursuit, self-regulation, and successful ageing.

It is important to note that different terminologies are used in the relevant literature to describe older adults. For the purpose of the present research, the term "older adults" will be used throughout, and we define this term as the age category comprising individuals who are 50 years and older.

\section{Theoretical Background}

\subsection{Age Stereotypes and Well-being}

A prevailing perspective in stereotype research is the notion that stereotypes are mental representations that support the interpretation of information in the social environment (Augoustinos \& Walker, 1998). Correspondingly, age stereotypes are defined as schemata or mental representations about older adults, their life, their experiences, and their behavior which may be positive, negative, or unrelated to valence (Hummert, 1999). According to the stereotype content model (Fiske et al., 2007), the stereotype of older adults represents a typical mixed-valence stereotype comprising attributes reflecting warmth and attributes reflecting low competence.

The ambiguity that the perception of age possesses suggests that contextual factors may have a greater impact on the evaluation of older adults than they may portray on other demographic groups, like gender (Perry \& Finkelstein, 1999). In fact, researchers consider age stereotypes as multidimensional and context-specific (Kite et al., 2005). There is little reason to assume that age stereotypes are only negative. Gluth, Ebener, and Schmiedek (2010) examined age stereotypes across several different dimensions. Older adults were perceived as being less active and adaptive to change, but as more autonomous than younger adults. These differences are also apparent in the context-dependent discrimination against older adults. Diekman and Hirnisey (2007) found in an experiment that an older candidate, but not a younger candidate, was perceived as less suitable for a company 
associated with rapid changes than for a company with a stable work environment. Interestingly, stereotypic expectations concerning older adults were less negative when participants had to select a candidate for the company with the stable work environment. In this case, participants even preferred the older candidate over the younger candidate.

Taking such differences in age stereotypes between contexts into account, Kornadt and Rothermund (2011) suggested to assess age stereotypes in various domains, such as physical and mental fitness, family and partnership, friends and acquaintances, and leisure activities. They found that evaluations of older adults differed markedly between these different domains, with the most negative ratings occurring for domains such as health and fitness, whereas more positive evaluations were observed as regards the domain family and partnerships. Such findings further indicate the existence of context dependencies in how older adults are perceived, and they suggest that the activation of specific age-stereotypic attributes can be dependent on the context in which an older adult is encountered.

Researchers postulate that age stereotypes are acquired at a young age and are integrated into the self-image throughout the lifespan (Levy, 2003), and that they affect perceptions and expectations of older adults, which can subsequently act as self-fulfilling prophecies (Levy \& Leifheit-Limson, 2009; Wurm et al., 2013). The proposition of age stereotypes as a driving force for self-fulfilling prophecies has been supported by research in the field of health psychology. Studies have shown, for example, that individuals with positive age stereotypes had a more positive expectation of recovery after a life-threatening event compared to individuals with more negative age stereotypes (Levy, Slade, May, \& Carracciolo, 2006), were characterized by higher self-efficacy (Levy et al., 2000; Levy et al., 2000), and were more likely to engage in physical activity (Sarkisian et al., 2005).

Prior studies also identified a link between positive age stereotypes and satisfaction with life (Kornadt \& Rothermund, 2011; Mock, \& Eibach, 2011; Rothermund, 2005; Shenkman et al., 2018) and self-esteem (Ward, 1977). In a longitudinal survey with two waves over 10 years, Mock and Eibach (2011) found that age attitudes measured in the first wave were significantly correlated with affect and satisfaction with life measured in the second wave. Shenkman et al. (2018) reported that individuals with more positive attitudes towards aging suffered less from depressive symptoms and reported a higher level of happiness. Kornadt and Rothermund (2011) found a positive association of age stereotypes and satisfaction with life, as well. In line with the idea that age stereotypes become more self-relevant with increasing age, they moreover observed that this positive relationship increased with the age of the participants. Based on the results summarized above, we formulated Hypothesis 1 .

Hypothesis 1: Positive age stereotypes will be positively related to well-being.

Regarding this hypothesis, it is important to clarify our understanding of age stereotypes and self-perception of ageing as separate concepts which are related, but not identical constructs. Self-perceptions of ageing capture individual experiences at the level of a person and "refer to individuals' perception of their own age and ageing" (Kotter-Grühn \& Hess, 2012; p. 563), while age stereotypes refer to the socially shared perceptions of older adults. The individual self-perception of ageing can differ importantly from the general representations of older adults in the society which are reflected in age stereotypes (Lacey et al., 2006; Pinquart, 2002; Rothermund, 2005). Individuals may perceive the decline of their abilities as worse or better than what they expect for others. The difference between age stereotypes and self-perception of ageing is also evident in their measurement. 
Age-stereotypes are usually assessed with items that refer to older adults in general (Kornadt \& Rothermund, 2011), while self-perception of ageing is measured with questions that focus on the individuals' own experiences (Levy, Slade, Kunkel \& Kasl, 2002; Rothermund, 2005).

\subsection{Selection, Optimization, and Compensation as Potential Mediators of Associations of Age Stereotypes and Well-Being}

While previous research on age stereotypes has focused on self-efficacy, concrete behaviors, and performance (Levy, 2003, 2009), little attention has been devoted to the question of how specific strategies of adaptation in goal pursuit are associated with age stereotypes. Such strategies are, however, fundamental to successful ageing, as requirements and resources change when individuals grow older (Freund, 2008). The SOC model of selection (S) optimization $(\mathrm{O})$ with compensation $(\mathrm{C})$ is a prominent theory describing such strategies (Freund \& Baltes, 1999). It proposes that strategies that help maximize the outcomes in goal pursuit are accompanied by strategies that prevent or limit losses. A strategy that relates to maximizing the desired outcomes is termed optimization. This strategy refers to the acquisition of resources and effort. For example, to achieve a goal, a person may increase his or her engagement. The strategies of selection and compensation are considered strategies that are related to the threat of potential losses. Selection means selecting the most important goals and giving up less important goals if not all desired goals can be achieved. Compensation refers to the substitution of resources which are depleted or no longer available. For instance, individuals might ask for help to compensate for observed physical limitations.

Studies have repeatedly shown a positive association of engagement in SOC strategies and well-being (Freund \& Baltes, 1998; MacLeod et al., 2008; Tovel \& Carmel, 2014). In a study with older participants, Freund and Baltes (1998) found a positive correlation between engagement in SOC strategies and life satisfaction, reduced inner restlessness, and reduced feelings of loneliness. Freund and Baltes (2002) and Jopp and Smith (2006) reported similar results.

Given that positive age stereotypes lead to the perception that both changing undesirable states and maintaining desired states is possible (Levy, 2003), we suppose that individuals with positive age stereotypes are more likely to engage in selection, optimization, and compensation, and that the application of these strategies mediates the relation between age stereotypes and well-being.

Hypothesis 2: Positive age stereotypes will be positively related to engagement in strategies of selection, optimization, and compensation.

Hypothesis 3: The relation between positive age stereotype and well-being will be mediated by engagement in the strategies of selection, optimization, and compensation.

While extant research indicates an impact of the SOC strategies on well-being, research on the relationship between age stereotypes and SOC strategies is scarce. $\mathrm{Ng}$ and Law (2014) argue that older workers are faced with negative age stereotypes in their working environment, but that they might use SOC strategies to maintain their functioning. However, they did not empirically test the relation of individual differences in age stereotypes and the use of SOC strategies, and they did not discuss the effects of 
positive stereotypes. Wurm et al. (2013) found in a study that older adults who perceive their own ageing process to be characterized by losses of health and energy show less engagement in SOC strategies. However, the authors assessed the self-perception of the ageing process and not individual differences in age stereotypes. Hence, even if it is argued that age stereotypes or self-perceptions of ageing are related to SOC strategies more evidence is needed to provide a substantive assessment of this relationship.

\subsection{Regulatory Focus as Potential Moderator of Associations Linking Age Stereotypes to Well-Being}

Even if stereotypes often have strong effects, they do not affect the experiences and behaviors to the same extent in all individuals (Shapiro \& Neuberg, 2007). A moderator of the stereotype effects discussed by researchers is the regulatory focus (Gaillard et al., 2011). The regulatory focus of individuals includes two self-regulatory strategies that individuals can apply in pursuing goals (Higgins, 1997, 1998). Individuals with a promotion focus are motivated to achieve their personal goals through effort and eagerness (Florack et al., 2005; Florack et al., 2013; Florack, Palcu et al., 2013). They possess trust in their own abilities to achieve a goal and are convinced that they will succeed in achieving it (Grant \& Higgins, 2003). Individuals in a prevention focus, by contrast, are driven by the need for safety, and a sense of duty (Florack, Keller, \& Palcu, 2013; Florack, Palcu, et al., 2013). Prevention-focused individuals focus their attention mainly on maintaining the status quo and achieving minimal goals (Leder, Florack, \& Keller, 2013, 2015).

Two arguments suggest that age stereotypes are less likely to affect older adults if promotion focus increases and prevention focus decreases. Firstly, people with a promotion focus are less sensitive to negative expectancies than those with prevention focus (Keller \& Bless, 2008). Secondly, promotion-focused individuals tend to construe themselves independently of their social environment and are less focused on what one should do than prevention-focused individuals (Lee \& Aaker, 2004). Promotion-focused individuals tend to follow their own preferences (Florack et al., 2010; Florack, Keller, et al., 2013; Florack, Palcu, et al., 2013).

First evidence for the moderating role of regulatory focus for the effects of stereotypes on behavior was provided by Gaillard et al. (2011). The researchers exposed older adults either to positive or negative stereotypic expectations prior to a test regarding the drivers' license examination. They found that the negative stereotypes had less detrimental effects on the test performance of the older adults when a promotion focus, compared to a prevention, focus was induced.

Based on the reasoning that regulatory focus functions as a potential moderator that affects the influence of stereotypes (Gaillard et al., 2011) through debilitating effects of negative expectancies (Keller \& Bless, 2008) and the social environment (Lee \& Aaker, 2004), and the argumentation that regulatory focus depends not only on situational factors but also on a trait-like variable based on socialization and learning (Higgins et al., 2001), we hypothesized that differences in a chronic regulatory focus also moderate the effects of age stereotypes.

Hypothesis 4a: With an increase in promotion focus the relationship between age stereotypes and well-being will decrease. 
Hypothesis 4b: With an increase in prevention focus the relationship between age stereotypes and well-being will increase.

\subsection{Summary and Rationale for Study 1}

Based on previous research, we hypothesized that positive age stereotypes are positively related to well-being. We further supposed that individuals with more positive age stereotypes are more likely to engage in the self-regulatory strategies of selection, optimization, and compensation which, in turn, mediate the relation between age stereotypes and wellbeing. However, since not all older adults integrate age stereotypes to the same extent into their self-concept, we expected that the effects of age stereotypes on the engagement in SOC strategies and well-being will decrease among those who demonstrate an increased promotion focus and a decreased prevention focus.

In Study 1, we tested Hypotheses 1 to $4 \mathrm{~b}$ in a cross-sectional study with older participants. The proposed model including mediation and moderation processes is depicted in Fig. 1. We measured age stereotypes across different domains (Kornadt \& Rothermund, 2011) and used established measures of SOC strategies (Baltes, Baltes, Freund, \& Lang, 1999) and regulatory focus (Higgins et al., 2001). In addition, we considered the breadth of the concept of well-being and assessed affect balance (Diener et al., 2010), satisfaction with life (Diener et al., 1985), and presence and search for meaning in life (Steger et al., 2006). Furthermore, we measured the positivity of expectations in life with the life orientation test (Scheier et al., 1994).

Our assessment of well-being is based on the view that well-being is a multidimensional construct (Diener et al., 1999), and the reasoning that more research is needed to differentiate between different types of well-being (Diener \& Chan, 2011). In particular, our conceptualization refers to the understanding that subjective well-being is based on cognitive and affective components (Diener et al., 2002, p. 63) which are both expected to contribute to health and longevity (Diener \& Chan, 2011). Affective well-being refers to positive and negative experiences, and it is often summarized as affect balance with high

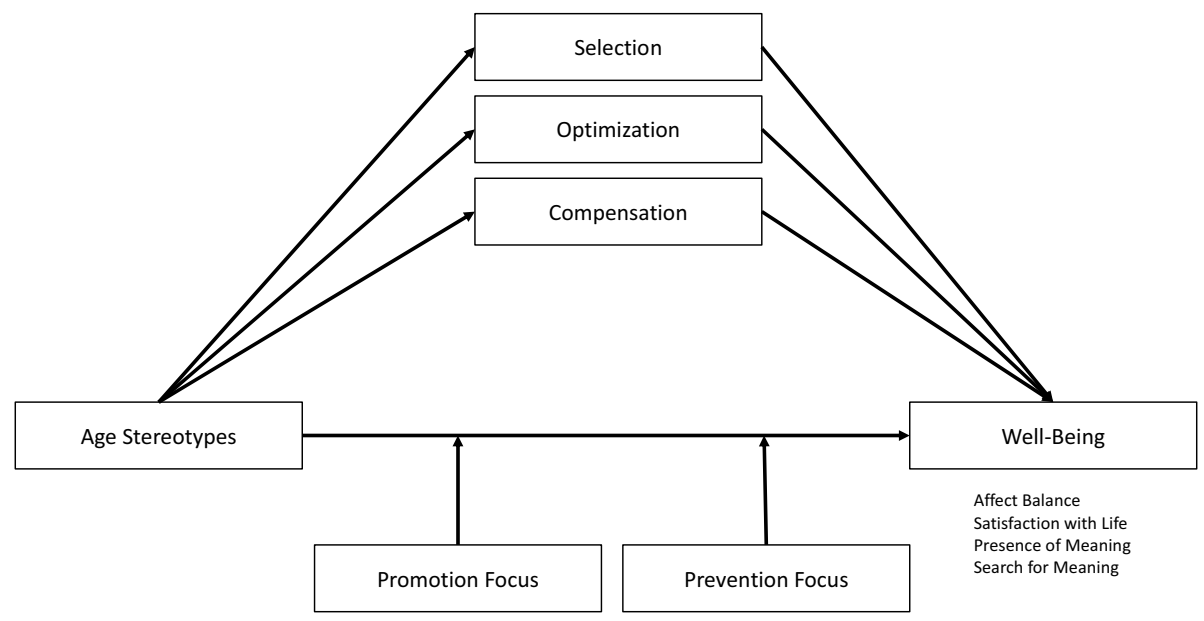

Fig. 1 Conceptual model for the effects of age stereotypes on well-being mediated by selection, optimization, and compensation and the moderation by Promotion and Prevention Focus (Study 1). Besides wellbeing we also measured positive expectations as an additional dependent measure 
values indicating a higher frequency of positive compared to negative affective experiences (Diener et al., 2010). Core aspects of the cognitive well-being include satisfaction with life (Diener et al., 1985) and perceived meaning in life (Steger et al., 2006). While satisfaction with life represents a global assessment of life, meaning in life refers to the purposefulness of life and the perception that life is goal directed and fulfilling (Reker \& Wong, 1988). In addition to satisfaction with life, we assessed the meaning in life, because we expected this component of well-being to be highly relevant for older adults. In particular, we supposed that the application of SOC strategies supports the pursuit of goals and thus the perception of a purposeful and meaningful life among older adults. However, it is important to distinguish the presence of meaning in life from the search for meaning. We assessed the search for meaning to complement our measures, but we have to note that the hypotheses and the existing evidence were less clear for this variable (Steger et al., 2006).

\section{Study 1}

\subsection{Method}

\subsubsection{Participants}

In order to recruit participants, we contacted the Austrian senior citizens' federation and the Pensioners' Association (Austria) and used our social networks to encourage older adults to participate in our study. The questionnaire was administered using the survey software Unipark (Questback). We informed the participants that the topic of the study was ageing. Six hundred and sixty-six participants (427 females, 239 males) completed the questionnaire. The age of the participants ranged between 50 and 89 years $(M=69.35, S D=7.36)$.

\subsubsection{Measures}

Before participants started with the questionnaire, they received a consent form. Participants who agreed to the conditions received the questionnaire and answered questions about their demographics including gender, age, marital status, and professional status. The language of the questionnaire was German.

We measured age stereotypes in five different life domains with adapted questions from Kornadt and Rothermund (2011). The selected life domains were family and partnership (3 items; e.g., "Old people...do not lead a fulfilling relationship vs. lead a fulfilling relationship"; Cronbach's alpha $=0.68$ ), friends and acquaintances ( 3 items; e.g., "Old people... have few friends and acquaintances vs. have many friends and acquaintances"; Cronbach's alpha $=0.85$ ), leisure activities and social or civic commitment (4 items; e.g., "Old people...show little commitment to others vs. show a lot of commitment to others"; Cronbach's alpha $=0.85$ ), personality and way of living ( 3 items; e.g., "Old people...have a lot to complain about vs. are open and tolerant"; Cronbach's alpha $=0.78)$, work and employment ( 3 items; e.g., "Old people... have difficulties in doing a good job vs. have no difficulties in doing a good job."; Cronbach's alpha $=0.70$ ) and physical and mental fitness, health, and appearance (5 items; e.g., "Old people... are often ill vs. ... are rarely ill"; Cronbach's alpha $=0.85$ ). In total, participants had to rate 21 questions on an 8-point bipolar scale. In addition, we built an overall stereotype measure by averaging all age stereotypes items $($ Cronbach's alpha $=0.93)$. High values indicate positive age stereotypes. 
To measure the three self-regulatory strategies of selection, optimization, and compensation, we used a short version of the SOC questionnaire (Baltes et al., 1999) that included 12 items measured with a bipolar 5-point scale. There were two response options for each item: one option reflecting SOC strategy use, and the other option reflecting behavior unrelated to SOC strategy use. Selection was measured with two subscales: Elective selection (3 items; e.g., "I concentrate all my energy on few things" vs. "I divide my energy among many things"; Cronbach's alpha =0.73), and loss-based selection (3 items; e.g., "When things don't go as well as before, I choose one or two important goals" vs. "When things don't go as well as before, I still try to keep all my goals"; Cronbach's alpha $=0.70$ ). Since the two scales were correlated $(r=0.50, p<0.001)$, we computed a composite scale with all items to measure selection (Cronbach's alpha $=0.78$ ). Optimization was measured with three items (e.g., "I make every effort to achieve a given goal" vs. "I prefer to wait for a while and see if things will work out by themselves"; Cronbach's alpha $=0.79$ ) as well as compensation (e.g., "When things don't go as well as they used to, I keep trying other ways until I can achieve the same result I used to" vs. "When things don't go as well as they used to, I accept it."; Cronbach's alpha $=0.69$ ). High values indicate engagement in the underlying self-regulatory strategy.

We measured affect balance with the Short Positive Affect and Negative Affect Scale (SPANE-B; Diener et al., 2010). This scale is based on a positive and a negative affect subscale. Participants have to indicate how much they have experienced positive (e.g., "happy"; Cronbach's alpha=0.88) and negative (e.g., "sad"; Cronbach's alpha =0.83) feelings over the previous 4 weeks on a 5 -point scale $(1=$ very rarely or never, $5=$ very often or always). The scores for each subscale were summed up and affect balance was computed as the difference between the positive and negative subscale. Scores can range from -24 to 24 with higher values indicating greater happiness.

To measure satisfaction with life, we applied the German version of the Satisfaction with Life Scale (SWLS; Diener et al., 1985; German version by Glaesmer et al., 2011) with 5 items (e.g., "I am satisfied with my life"; Cronbach's alpha=0.84). Participants answered on a 7 -point scale $(1=$ do not agree at all, $7=$ totally agree $)$. High values indicate high satisfaction with life.

We applied the Meaning in Life Questionnaire (MLQ; Steger et al., 2006) to measure presence of meaning with five items (e.g., "My life has a clear sense of purpose"; Cronbach's alpha $=0.93$ ), and search for meaning with five items (e.g., "I am looking for something that makes my life feel meaningful"; Cronbach's alpha=0.93). Participants answered the questions on a 7 -point scale $(1=$ not at all, $7=$ very much $)$. High values indicate strong presence of or search for meaning in life.

To assess positive expectations, we used the German version (Glaesmer et al., 2008) of the life orientation test (LOT-R) developed by Scheier et al. (1994). This scale consists of seven relevant items (e.g., "In uncertain times, I usually expect the best"; Cronbach's alpha $=0.70)$ and three filler items. Participants answered the questions on a 5-point scale $(1=$ not at all, $5=$ very $m u c h)$. High values indicate positive expectations in life.

Promotion and prevention focus were assessed with the Regulatory Focus Questionnaire (RFQ; Higgins et al., 2001). The questionnaire contains 11 items, which participants had to rate on a 5 -point scale (ranging from $1=$ never or seldom to $5=$ very often or $1=$ certainly false to $5=$ certainly true). Six items assess promotion-focused self-regulation (e.g., "I have found very few hobbies or activities in my life that capture my interest or motivate me to put effort into them", reverse coded; Cronbach's alpha =0.71). Five items assess prevention-focused self-regulation (e.g., "How often did you obey rules and regulations that were established by your parents"). Due to insufficient reliability of the prevention scale 
(Cronbach's alpha $=0.55$ ), we excluded one item ("Not being careful enough has gotten me into trouble at times"). The resulting Cronbach's alpha was 0.70 . High values indicate a high promotion and a high prevention focus.

\subsection{Data Analysis}

For data analysis, we used SPSS (version 24.0) and the macro PROCESS (version 3.2) by Hayes (2012). First, Pearson correlations were calculated to test the relationships between the study variables. Second, we applied mediation analyses to test whether engagement in SOC strategies mediates the relationship between positive age stereotypes and well-being. Third, we calculated moderator analyses to test whether correlations of age stereotypes with engagement in SOC strategies and well-being were moderated by promotion- and prevention-focused self-regulation. Finally, we applied multiple regressions to assess the relevance of domain-specific age stereotypes in the prediction of SOC strategies and wellbeing. Also, we tested possible moderations by gender. Finally, we assessed the relevance of domain-specific age stereotypes in the prediction of SOC strategies and well-being.

\subsection{Results}

\subsubsection{Preliminary Analyses}

Descriptive statistics and correlations between the measures of this study are reported in Table 1. We found positive correlations of the composite scale of age stereotypes with all well-being measures ranging from $r=0.32$ to $r=0.46$ with the exception of search for meaning, which showed a weak negative correlation with age stereotypes. Furthermore, age stereotypes were positively correlated with positive expectations. Regarding the engagement in the SOC strategies, the composite scale of age stereotypes was positively correlated with optimization, and compensation, but not in the same direction with selection. Optimization and compensation, but not selection, were also consistently positively correlated with positive expectations and the different measures of well-being.

\subsubsection{Mediation by SOC Strategies}

To test whether the correlations between age stereotypes and well-being were mediated by SOC strategies, we calculated mediation analyses with the SPSS PROCESS macro (model 4) by Hayes (2012). An overview of the indirect effects of age stereotypes on the different kinds of well-being via engagement in SOC strategies is depicted in Table 2. We found consistent indirect effects of age stereotypes on affect balance, satisfaction with life, presence of meaning, and positive expectations through optimization, but in contrast to our expectations not through selection and compensation. We observed no mediating effects of engagement in SOC strategies on search for meaning.

As research has shown that gender is a relevant variable in self-regulatory engagement (Wiese et al., 2000), we further examined whether the indirect effects were moderated by gender. In detail, we tested the moderation by gender for the effects of age stereotypes on SOC strategies (PROCESS model 8) and for the effects of SOC strategies on wellbeing (PROCESS model 15) within the mediation models. The test of the moderation of the direct effect of age stereotypes on well-being was included in all models, as well. The 


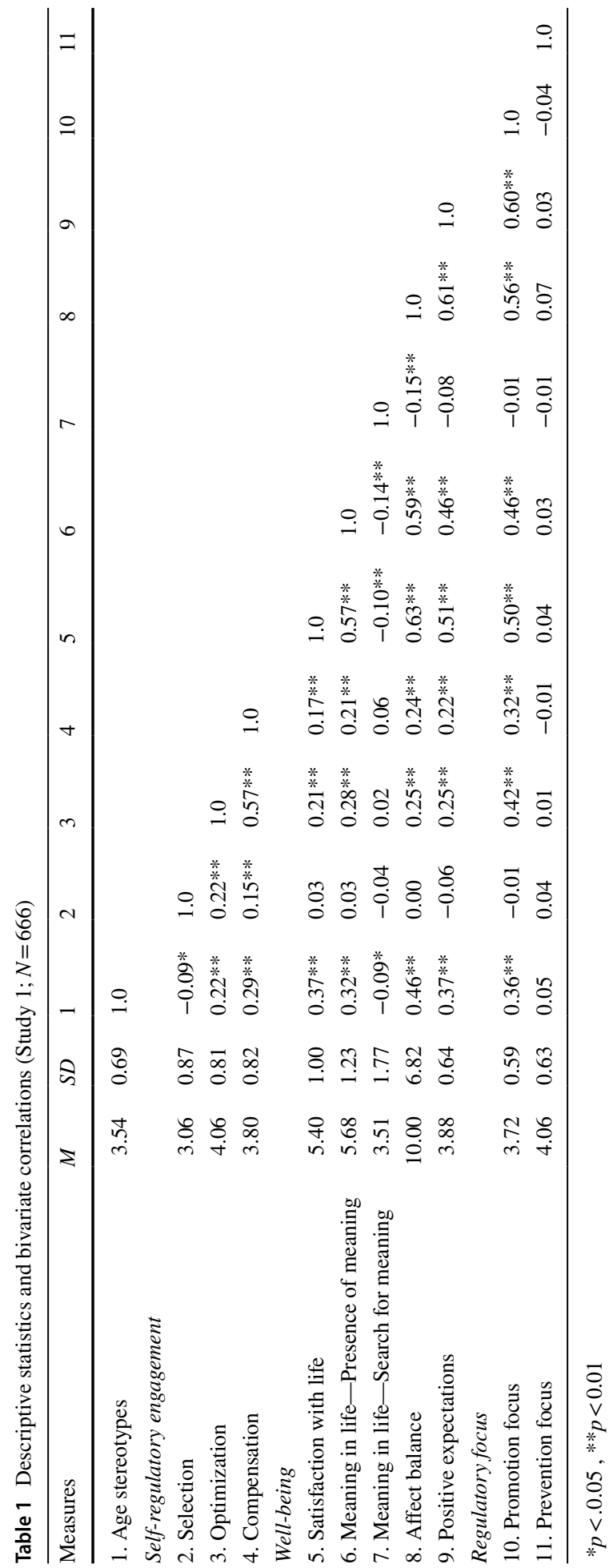


Table 2 The Bootstrap 95\% confidence intervals (Lower and Upper Bounds) for the indirect effects of age stereotypes through self-regulatory engagement on well-being (Study 1)

\begin{tabular}{|c|c|c|c|c|c|c|c|c|c|c|}
\hline \multirow[t]{4}{*}{ Mediators } & \multicolumn{10}{|c|}{ Predictor variable: Age stereotypes } \\
\hline & \multirow{2}{*}{\multicolumn{2}{|c|}{$\begin{array}{l}\text { DV Affect bal- } \\
\text { ance } \\
95 \% \text { CI }\end{array}$}} & \multirow{2}{*}{\multicolumn{2}{|c|}{$\begin{array}{l}\text { DV Satisfaction } \\
\text { with life } \\
95 \% \mathrm{CI}\end{array}$}} & \multirow{2}{*}{\multicolumn{2}{|c|}{$\begin{array}{l}\text { DV Presence of } \\
\text { meaning } \\
95 \% \text { CI }\end{array}$}} & \multirow{2}{*}{\multicolumn{2}{|c|}{$\begin{array}{l}\text { DV Search for } \\
\text { meaning }\end{array}$}} & \multirow{2}{*}{\multicolumn{2}{|c|}{$\begin{array}{l}\text { DV Positive } \\
\text { expectations }\end{array}$}} \\
\hline & & & & & & & & & & \\
\hline & Lower & Upper & Lower & Upper & Lower & Upper & Lower & Upper & Lower & Upper \\
\hline Selection & -0.09 & 0.08 & -0.02 & 0.01 & -0.02 & 0.01 & -0.00 & 0.05 & -0.00 & 0.02 \\
\hline Optimization & 0.08 & 0.53 & 0.01 & 0.08 & 0.04 & 0.14 & -0.05 & 0.06 & 0.01 & 0.06 \\
\hline Compensation & -0.13 & 0.40 & -0.05 & 0.03 & -0.05 & 0.06 & -0.00 & 0.15 & -0.01 & 0.04 \\
\hline TOTAL & 0.11 & 0.74 & -0.01 & 0.08 & 0.03 & 0.15 & 0.02 & 0.17 & 0.03 & 0.08 \\
\hline
\end{tabular}

The indirect effect is significant when the confidence interval (CI) does not include zero. Bold font indicates statistical significance. DV: Dependent variables

analyses yielded no significant moderation of the direct or indirect effects of age stereotypes on well-being by gender, $b s \leq-0.19, p s>0.06$.

\subsubsection{Moderation by Regulatory Focus}

To test whether regulatory focus moderates the associations of positive age stereotypes with well-being, we applied the PROCESS macro (model 2) by Hayes (2012). Age stereotypes were entered as independent variable into the regression equations, promotion and prevention focus as moderators, the different kinds of well-being as dependent variables. An overview of the results is presented in Table 3. The significant interactions between age stereotypes and regulatory focus are depicted in Figs. 2 and 3. The promotion focus moderated the correlation between age stereotypes and different kinds of well-being, but it did not moderate effects on the search for meaning. As expected, we found that the correlation of age stereotypes with the well-being measures decreased with an increase in promotion focus. In contrast to our expectation, the prevention focus did not show moderation effects for these relations between age stereotypes and well-being. There was only a moderating effect of prevention focus for the linkage between age stereotypes and search for meaning. For participants with a stronger prevention focus, positive age stereotypes were negatively correlated with search for meaning, but not for those with a weak prevention focus. In addition, we applied PROCESS model 3 to test whether the moderating effects of regulatory focus on the linkage between age stereotypes and well-being differed for women and men. The analyses yielded no significant moderation by gender, $b s \leq 34, p s>0.11$.

\subsubsection{Domain-Specific Age Stereotypes}

The correlations between domain-specific age stereotypes and well-being measure were positive with the exception of the correlations with search for meaning (Table 4). Multiple regression analyses with the domain-specific age stereotypes as predictors and wellbeing measures as dependent variables (Table 5) yielded that, in particular, stereotypes in the domains "family and partnership" as well as "leisure activities and social or civic commitment" showed unique contributions to the prediction of the well-being measures. 


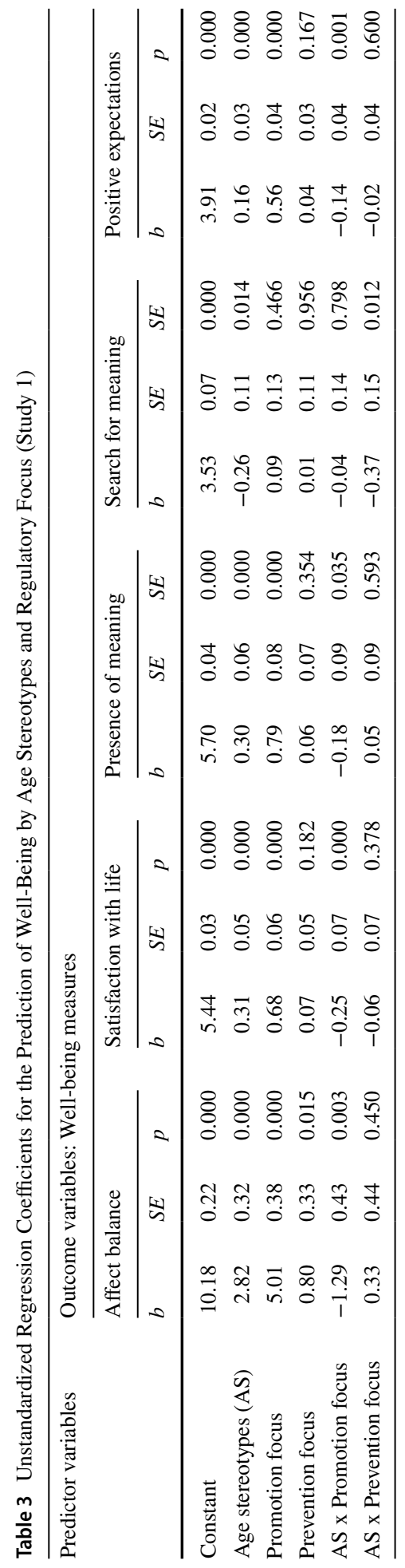



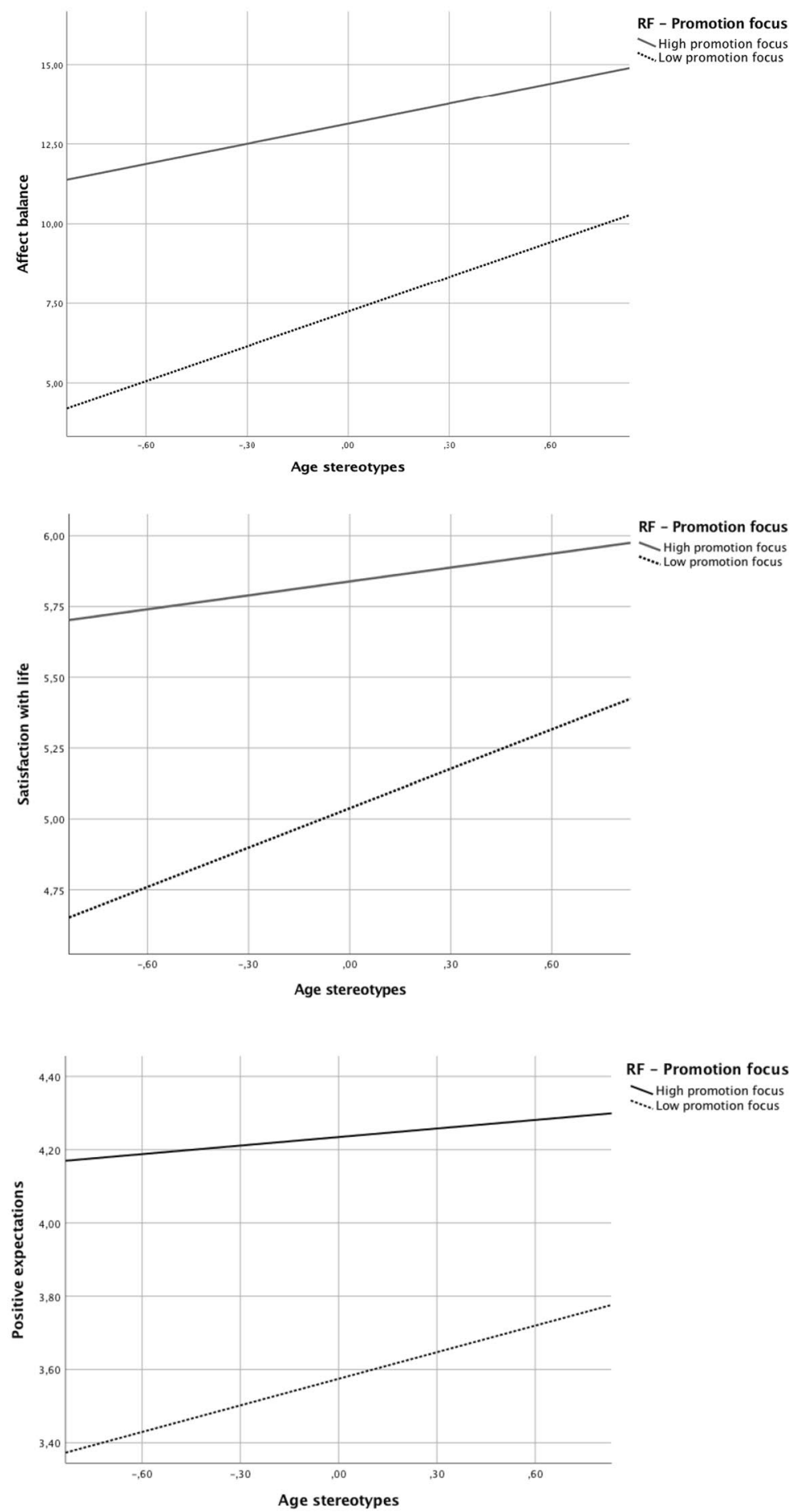

Fig. 2 Affect balance, satisfaction with life and positive expectations as a function of age stereotypes and regulatory focus $(N=666)$ 

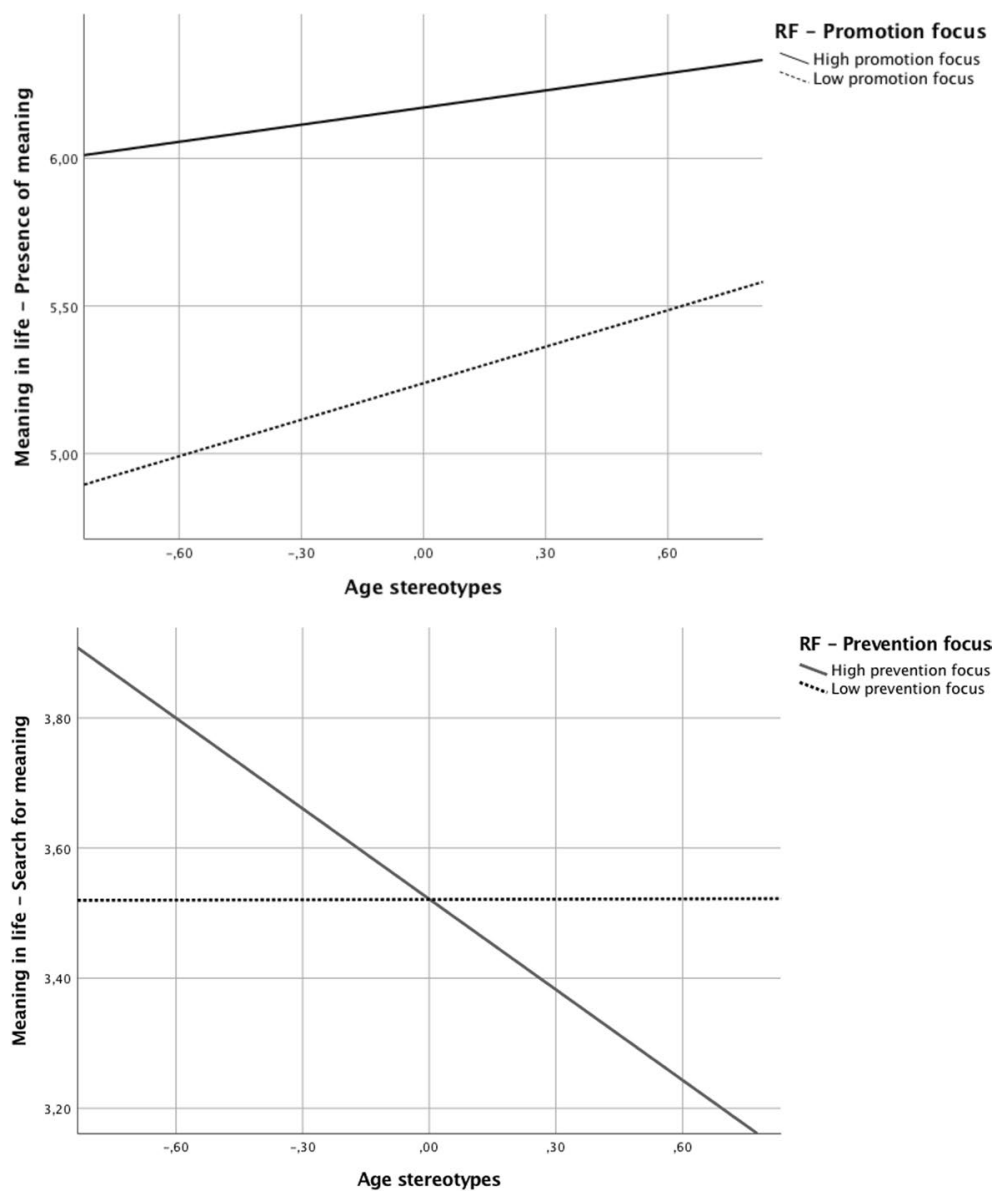

RF - Prevention focus High prevention focus ... Low prevention focus

Fig. 3 Presence and search for meaning in life as a function of age stereotypes and regulatory focus $(N=666)$

Multiple regressions with the engagement in SOC strategies as dependent measures (Table 6) showed that stereotypes in the domains "leisure activities and social or civic commitment" were significant positive predictors of engagement in optimization and compensation. In addition, stereotypes in the domains "friends and acquaintances", and "physical and mental fitness, health, and appearance" were significant positive predictors of engagement in compensation. Separate mediation analyses for the domain-specific age stereotypes illustrated that engagement in optimization is the most important mediator for the linkage between age stereotypes and well-being across the different stereotype domains. An overview of the mediation analyses for each stereotype domain is depicted in Table 7.

\subsection{Discussion}

In Study 1, we examined whether positive age stereotypes in various life domains are positively associated with different aspects of well-being. In accordance with our 


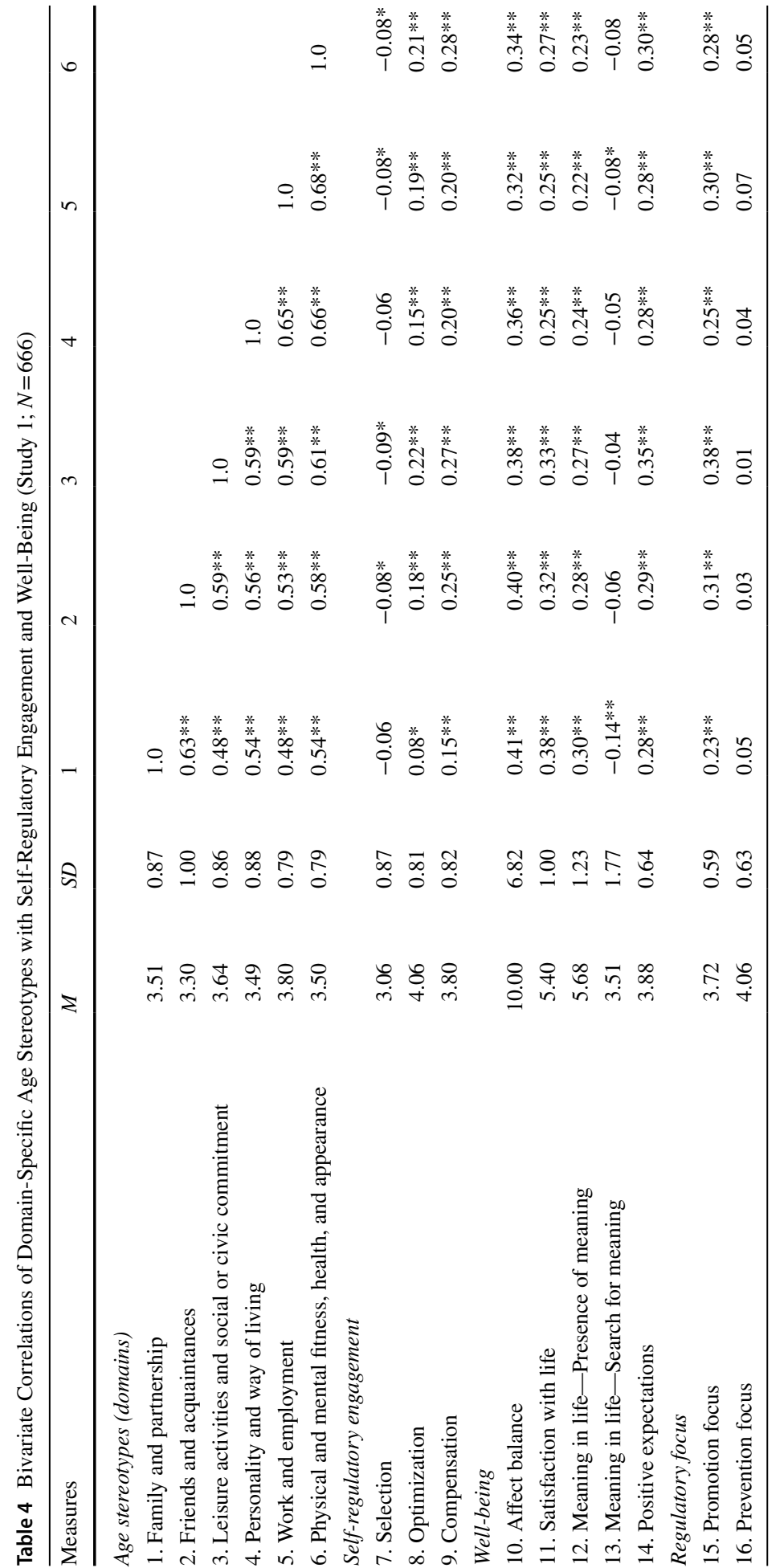

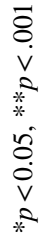




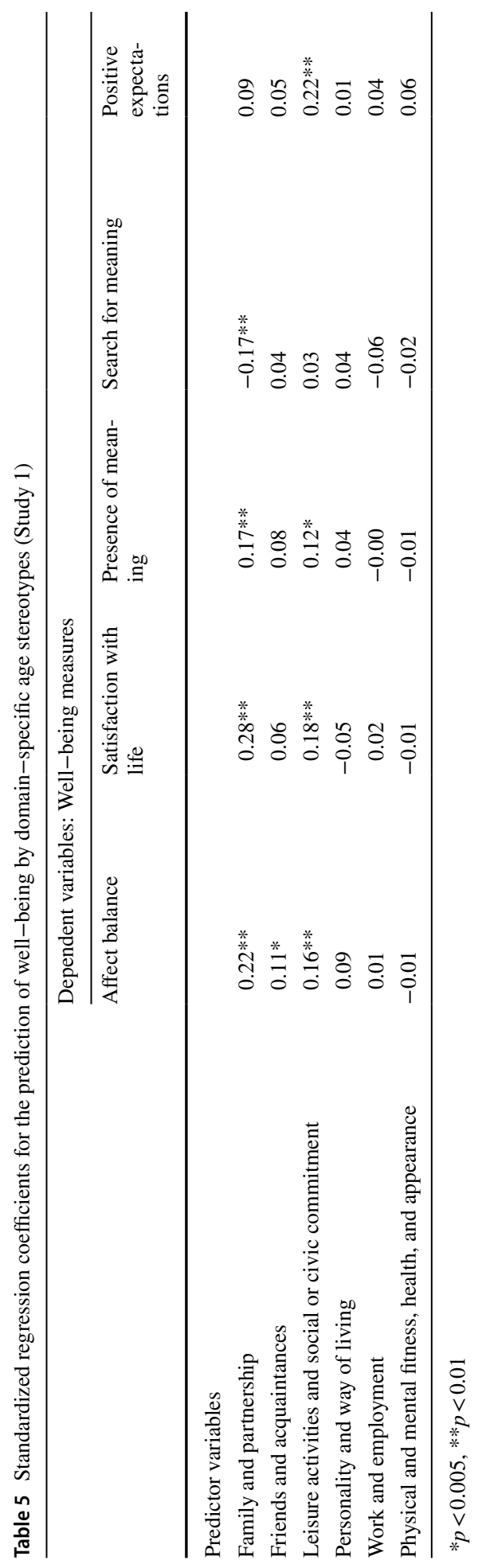


Table 6 Standardized Regression Coefficients for the Prediction of Self-Regulatory Engagement by Domain-Specific Age Stereotypes (Study 1)

Dependent variables: Self-regulatory engagement

Selection Optimization Compensation

\begin{tabular}{lccc}
\hline Predictor variables & & & \\
Family and partnership & 0.01 & $-0.11^{*}$ & -0.08 \\
Friends and acquaintances & -0.04 & 0.08 & $0.13^{*}$ \\
Leisure activities and social or civic commitment & -0.06 & $0.14^{* *}$ & $0.15^{* *}$ \\
Personality and way of living & 0.03 & -0.02 & -0.03 \\
Work and employment & -0.03 & 0.05 & -0.03 \\
Physical and mental fitness, health, and appearance & -0.03 & 0.11 & $0.19^{* *}$ \\
\hline
\end{tabular}

$* p<0.05, * * p<.01$

hypotheses, we observed the predicted relationship consistently across the different well-being indicators. Only search for meaning was not positively associated with age stereotypes. Extending previous research, we also found that the relationship between age stereotypes and well-being was mediated via the self-regulatory strategy of optimization. In contrast to our expectations, we did not observe mediation via selection and only in two aspects of well-being (affect balance and positive expectations) mediation via compensation strategies. However, the mediation by optimization is a first hint that self-regulatory engagement might at least partially explain the relation of age stereotypes to well-being.

The results of Study 1 also suggest that especially stereotypes in the domain of leisure activities and social or civic commitment are linked to self-regulatory engagement and well-being. Indeed, it is conceivable that these activities help older adults to maintain a high level of motivation and to find support. Also, it is interesting that positive stereotypes in the domain family and partnership more than in the domain friends and acquaintances show a unique contribution to the prediction of different well-being measures. The stereotypic expectation that individuals can play a meaningful role in the family also in older age might support the experience of meaning, positive affect, and satisfaction.

In addition, the present study revealed that the relationship between age stereotypes and well-being decreases with an increase in promotion focus. This finding is consistent with the theory that individuals with a strong promotion focus are more likely than individuals with a weak promotion focus to construe their self independently of others and the expectations conveyed by stereotypes in society.

Although the results were highly consistent for most well-being scales, the patterns observed for search for meaning were different. Previous research has already indicated that search for meaning differs from other aspects of well-being (Steger et al., 2006). While the presence of meaning is considered important for human functioning, the search for meaning has been interpreted as being distressing (Steger et al., 2006) which is congruent with the negative correlation with affect balance in the present study. Interestingly, this negative correlation increased with an increase in prevention focus. It seems that individuals with a prevention focus perceive a need to search for meaning in life when age stereotypes are negative, but not when they are positive. 


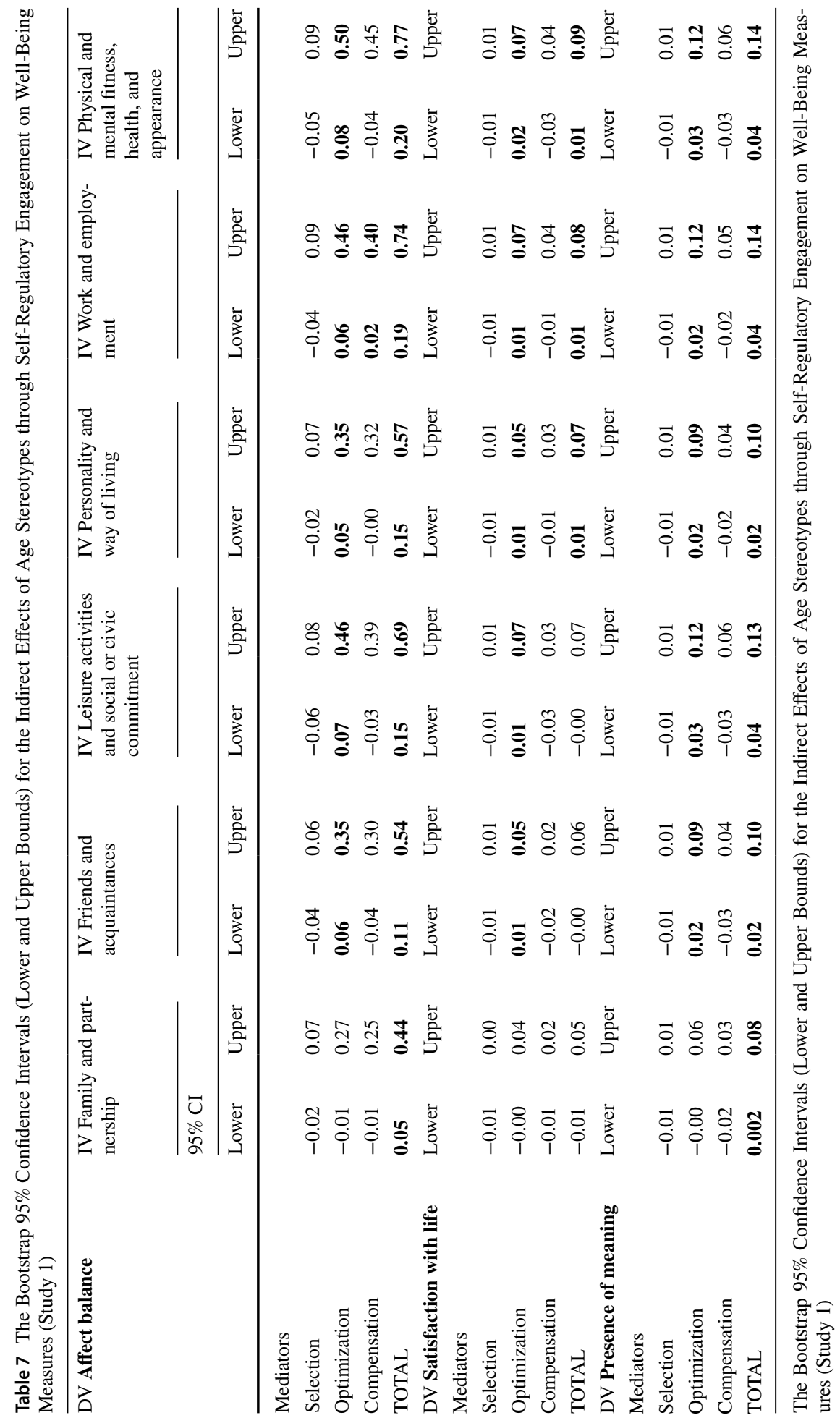




\section{Study 2}

Applying a cross-sectional design, Study 1 provided first indications that age stereotypes are related to well-being and that this relationship is mediated consistently via the selfregulatory strategy of optimization. However, a limitation of Study 1 is that all concepts were measured simultaneously. Therefore, we cannot rule out that certain state characteristics of the participants, such as mood, might have influenced the responses of the participants concerning age stereotypes and well-being. Additionally, Study 1 does not provide an answer to the question whether stereotypes, which existed at an earlier point in time, are related to the engagement in SOC strategies and the experience of well-being later on. To ensure that temporary states are not responsible for the correlations observed and to support the conclusions drawn about the effects of age stereotypes on SOC strategies and well-being, we analyzed longitudinal panel data in Study 2 which included measurements of age stereotypes, self-regulatory strategies and well-being at three points in time (i.e., in 2008, 2014, and 2017).

In detail, we tested in Study 2 the hypotheses that positive age stereotypes at a first measurement time will be related to well-being at a second and third measurement time (Hypothesis 1) and to self-regulatory strategies of selection, optimization, and compensation at a second and third measurement time (Hypotheses 2). Further, we investigated whether the relation between age stereotypes with well-being will be mediated via engagement in self-regulatory strategies (Hypothesis 3 ). The proposed model including mediation processes is depicted in Fig. 4.

To test our hypotheses, we used data from the scientific release of the German Ageing Survey (DEAS) provided by the Research Data Centre of the German Centre of Gerontology (DZA). The DEAS is a nationwide representative cross-sectional and longitudinal panel survey of the German population aged 50 and older. We selected the waves of 2008, 2014, and 2017, because these waves included measurements of age stereotypes (2008), well-being $(2008,2014,2017)$, and the engagement in SOC strategies $(2014,2017)$ so that the measurement of age stereotypes in 2008 could be used to predict the engagement in

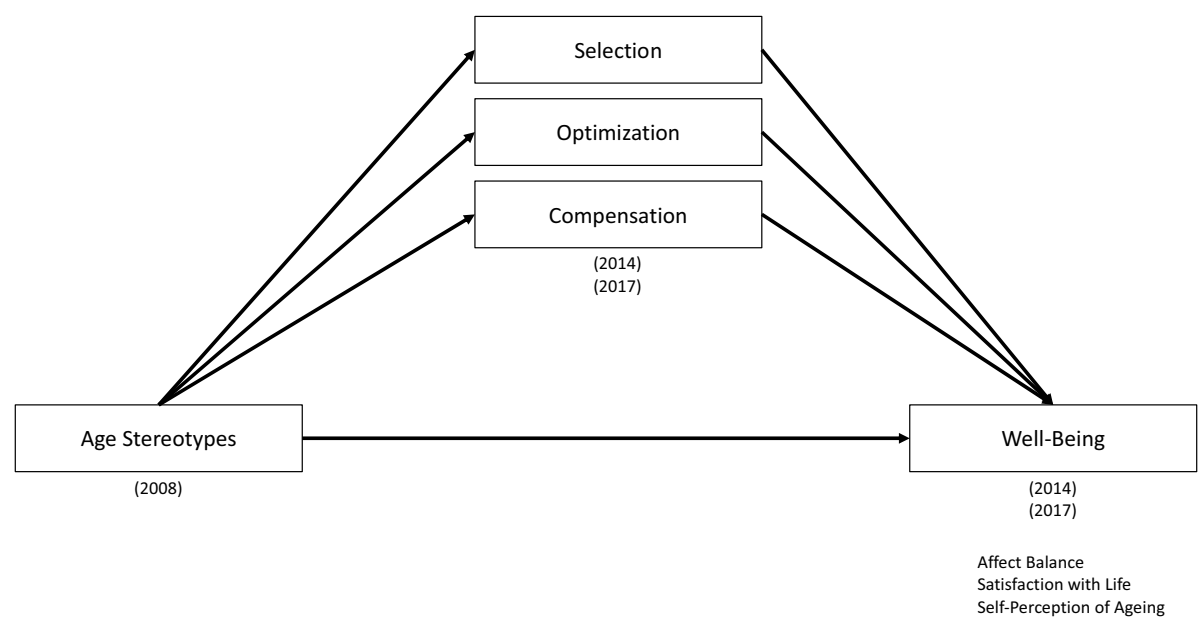

Fig. 4 Conceptual model for the effects of age stereotypes on well-being mediated by selection, optimization, and compensation (Study 2) 
SOC strategies and well-being at later points in time. In contrast to Study 1, the measures of age stereotypes and engagement in the SOC strategies were short measures with a reduced number of items. In particular, the measure of the SOC strategies was based on 4 items and did not use extensive subscales for selection, optimization, and compensation. The measures of well-being were similar to those in Study 1 and included measures of satisfaction with life, and affect balance, as well as self-perception of ageing, which we did not measure in Study 1. Search for meaning and presence of meaning were not assessed. Similar to Study 1, we controlled for gender in Study 2 and also included health status and socioeconomic status as control variables at the time the dependent measures were assessed, because previous research has shown that these variables are linked to affective well-being (Burr et al., 2011).

\subsection{Method}

\subsubsection{Participants}

The data set for our statistical analyses was based on 2325 participants (1165 females, 1160 males) who participated in 2008 as well as in the two following waves in 2014 and 2017. Only participants who were 50 years or older in 2008 and who took part in all three waves were included. The age of participants in 2008 ranged between 50 and 86 years $(M=63.39$, $S D=8.46)$.

\subsubsection{Measures}

Age stereotypes were measured with a composite scale with items according to different aspects of age stereotypes. Physical loss was measured with 4 items (e.g., "For most people, getting older means...that you are less energetic and fit"), social loss with 4 items (e.g., "For most people, getting older means...that you aren't really needed anymore"; Cronbach's alpha = 0.78), personal growth with 4 items (e.g., "For most people, getting older means...that you're still able to learn new things"), gains with 4 items (e.g., "For most people, getting older means...that you have a better idea of what you want"). In addition, general images of ageing in society were assessed with 5 items ("For most people, getting older means...that you are just as happy as in your younger years"). Participants answered each item on a 4-point scale $(1=$ strongly agree, $4=$ strongly disagree $)$. The items were recoded and averaged in a way that high values indicate positive age stereotypes (Cronbach's alpha $=0.87$ ).

The survey included a short measure of self-regulatory engagement with four items (Freund \& Baltes, 2002) that represented the SOC strategies. Two items measured selection ("I have set my goals clearly and stick to them"; "When I can't do something important the way I did before, I look for a new goal"). Optimization ("I do everything I can to realize my plans") and compensation ("When it becomes harder for me to get the same results, I keep trying harder until I can do it as well as before") were assessed with one item each. Participants answered on 4-point scales ( $1=$ strongly agree, $4=$ strongly disagree $)$. The items were recoded and averaged in a way that high values indicate engagement in selfregulation (2014: Cronbach's alpha $=0.78 ; 2017$ : Cronbach's alpha $=0.78$ ).

The survey included the Satisfaction with Life Scale (SWLS; Diener et al., 1985; 2008: Cronbach's alpha $=0.98 ; 2014$ : Cronbach's alpha $=0.85 ; 2017$ : Cronbach's alpha $=0.84$ ). 
Participants had to rate each item on a 4-point scale $(1=$ strongly agree, $4=$ strongly disagree). The items were averaged and high values indicate high satisfaction with life.

Affect balance was measured with an adapted version of the Positive and Negative Affect Scale (PANAS; Watson et al., 1988). Participants had to indicate how often they experienced positive (10 items: e.g., "enthusiastic"; 2008: Cronbach's alpha $=0.99 ; 2014$ : Cronbach's alpha $=0.81 ; 2017$ : Cronbach's alpha $=0.83)$ and negative $(10$ items: e.g., "distressed"; 2008: Cronbach's alpha $=0.99 ; 2014$ : Cronbach's alpha $=0.85 ; 2017$ : Cronbach's alpha $=0.85)$ feelings during the last months on a 5 -point scale $(1=$ never, $5=$ very often $)$. The scores for each subscale were summed up and affect balance was computed as the difference between positive and negative affect. Scores can range from -50 to 50 with higher values indicating greater happiness.

An adapted sub-scale of the Philadelphia Geriatric Center Morale Scale (Lawton, 1975) was used to measure self-perception of ageing. This scale included 5 items (e.g., "As I get older, things are better than I thought they would be"; 2008: Cronbach's alpha $=0.71 ; 2014$ : Cronbach's alpha $=0.72 ; 2017$ : Cronbach's alpha $=0.75)$ measuring self-perception of ageing on a 4-point scale ( $1=$ strongly agree, $4=$ strongly disagree $)$. The items were recoded and averaged in a way whereby high values indicate positive views on ageing.

Health status was measured with one item that asked participants if a doctor had ever told them that they had one or more different diseases out of a total of 19 listed (e.g., high cholesterol, diabetes, high blood pressure). Health status was derived from the sum score of the reported diseases, with a higher score indicating a worse health status of the participant.

Socioeconomic status was measured with one item that asked participants to rate their current standard of living. Participants answered on 5-point scales $(1=$ very good, $4=$ very $b a d)$. The item was recoded in a way that high values indicate high standard of living.

\subsection{Data Analysis}

Similar to Study 1, data analysis was performed using SPSS (version 24.0) and the PROCESS macro (version 3.2) by Hayes (2012). Pearson correlations were calculated to test the relationships between the relevant measures. In addition, we applied a mediation analysis to test whether engagement in the SOC strategies mediates the relationship between positive age stereotypes and well-being, and tested possible moderating effects by gender.

\subsection{Results}

\subsubsection{Preliminary Analyses}

Table 8 reports the descriptive statistics and correlations between the measures of interest. We found positive correlations of age stereotypes measured in 2008 with all well-being measures of the years 2008, 2014 and 2017 ranging between $r=0.08$ and $r=0.26$. Also, age stereotypes measured in the year 2008 correlated significantly with all SOC strategies measured in 2014 and 2017, ranging between $r=0.11$ and $r=0.15$. The SOC strategies measured in 2014 and 2017 correlated significantly with affect balance, satisfaction with life, and self-perception of ageing measured in the same years, ranging between $r=0.22$ and $r=0.40$. 


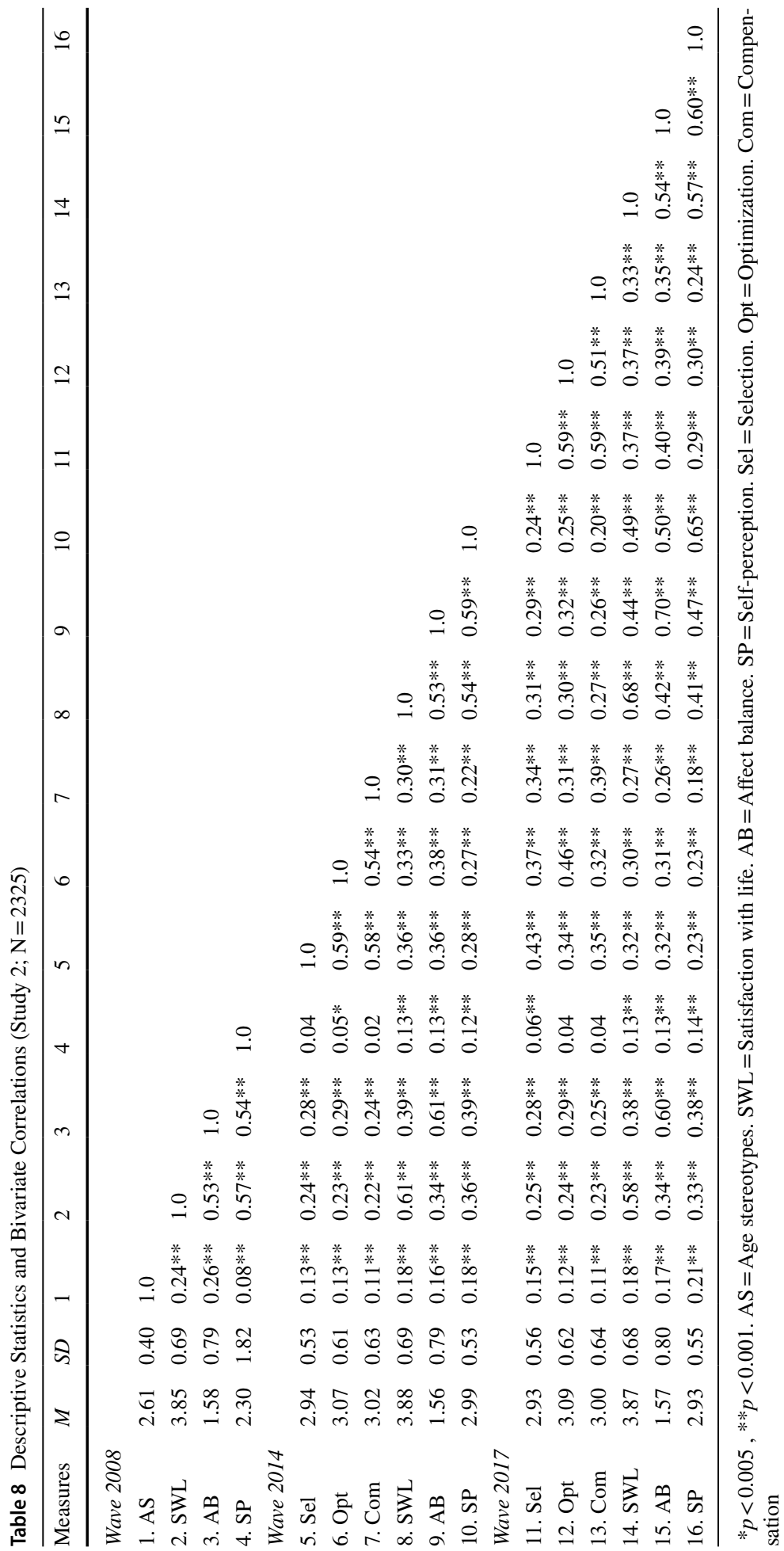


Table 9 The Bootstrap 95\% Confidence Intervals (Lower and Upper Bounds) for the Indirect Effects of Age Stereotypes (Wave 2008) through Self-Regulatory Engagement (Wave 2014) on Well-Being Measures (Wave 2014) (Study 2)

\begin{tabular}{|c|c|c|c|c|c|c|}
\hline \multirow[t]{4}{*}{ Mediators } & \multicolumn{6}{|c|}{ Predictor: Age stereotypes (Wave 2008) } \\
\hline & \multicolumn{2}{|c|}{$\begin{array}{l}\text { Satisfaction with } \\
\text { life (Wave 2014) }\end{array}$} & \multicolumn{2}{|c|}{$\begin{array}{l}\text { Affect balance } \\
\text { (Wave 2014) }\end{array}$} & \multicolumn{2}{|c|}{$\begin{array}{l}\text { Self-perception } \\
\text { of ageing } \\
\text { (Wave 2014) }\end{array}$} \\
\hline & \multicolumn{2}{|l|}{$95 \% \mathrm{CI}$} & \multicolumn{2}{|l|}{$95 \% \mathrm{CI}$} & \multicolumn{2}{|c|}{$95 \% \mathrm{CI}$} \\
\hline & Lower & Upper & Lower & Upper & Lower & Upper \\
\hline Selection & $\mathbf{0 . 0 3}$ & 0.07 & $\mathbf{0 . 0 3}$ & 0.07 & 0.02 & 0.04 \\
\hline Optimization & 0.02 & 0.05 & $\mathbf{0 . 0 3}$ & 0.08 & 0.01 & 0.04 \\
\hline Compensation & 0.004 & 0.03 & 0.004 & $\mathbf{0 . 0 3}$ & -0.00 & 0.01 \\
\hline TOTAL & 0.07 & 0.13 & 0.08 & 0.16 & 0.04 & 0.07 \\
\hline
\end{tabular}

The indirect effect is significant when the confidence interval (CI) does not include zero. Bold font indicates statistical significance

\begin{tabular}{|c|c|c|c|c|c|c|}
\hline \multirow[b]{4}{*}{ Mediators } & \multicolumn{6}{|c|}{ IV: Age Stereotypes (Wave 2008) } \\
\hline & \multicolumn{2}{|c|}{$\begin{array}{l}\text { DV: Satisfaction } \\
\text { with life (Wave } \\
\text { 2017) }\end{array}$} & \multicolumn{2}{|c|}{$\begin{array}{l}\text { DV: Affect } \\
\text { balance (Wave } \\
2017 \text { ) }\end{array}$} & \multicolumn{2}{|c|}{$\begin{array}{l}\text { DV: Self- } \\
\text { perception of } \\
\text { ageing (Wave } \\
\text { 2017) }\end{array}$} \\
\hline & \multicolumn{2}{|l|}{$95 \% \mathrm{CI}$} & \multicolumn{2}{|c|}{$95 \% \mathrm{CI}$} & \multicolumn{2}{|l|}{$95 \% \mathrm{CI}$} \\
\hline & Lower & Upper & Lower & Upper & Lower & Upper \\
\hline Selection & $\mathbf{0 . 0 3}$ & 0.07 & 0.04 & 0.09 & 0.01 & 0.04 \\
\hline Optimization & 0.02 & 0.06 & $\mathbf{0 . 0 3}$ & 0.07 & 0.01 & 0.04 \\
\hline Compensation & 0.01 & 0.03 & 0.01 & 0.04 & 0.001 & 0.02 \\
\hline TOTAL & 0.07 & 0.14 & 0.09 & 0.17 & 0.04 & 0.08 \\
\hline
\end{tabular}

The indirect effect is significant when the confidence interval (CI) does not include zero. Bold font indicates statistical significance
Table 10 The Bootstrap 95\% Confidence Intervals (Lower and Upper Bounds) for the Indirect Effects of Age Stereotypes (Wave 2008) through Self-Regulatory Engagement (Wave 2017) on Well-Being Measures (Wave 2017) (Study 2)

\subsubsection{Mediation by SOC Strategies}

We computed mediation analyses using the SPSS PROCESS macro (model 4) by Hayes (2012) to test whether the correlations between age stereotypes and well-being were mediated by self-regulatory engagement in the SOC strategies over a period of 6 and 9 years. Tables 9 and 10 provide an overview of the indirect effects of age stereotypes on wellbeing through self-regulatory engagement in the SOC strategies measured in 2014 and 2017. We found consistent indirect effects for all well-being measures. The indirect effects were significant for engagement in all SOC strategies for all dependent measures except compensation, which did not mediate the relationship of age stereotypes with self-perception of ageing (Wave 2 in 2014).

As in Study 1, we computed moderated mediation analyses (Models 8 and 15) to test whether the observed mediation effects varied by gender. In addition to Study 1 we also integrated health status and socioeconomic status at the time the dependent measures were assessed as potential moderators in our analyses. Again, no consistent gender differences 
were found, with the exception of the effect of age stereotypes on satisfaction with life $(b=-0.13, \mathrm{SE}=0.06, t=-2.23, p=0.021)$ and affect balance $(b=0.21, \mathrm{SE}=0.07, t=3.14$, $p=0.002$ ), both measured in Wave 2014, mediated by compensation (moderated path from compensation to well-being). However, the moderation effect was not consistent with the first mediation being stronger for men than for women and the second mediation being stronger for women than for men. Similarly, there were no consistent differences in relation to participants' health status or socioeconomic status. We only found moderation effects for age stereotypes on satisfaction with life (Wave 2014) $(b=0.06, \mathrm{SE}=0.02, t=3.35$, $p=0.001$ ), mediated by optimization, with a stronger mediation for participants with bad health status (moderated path from age stereotypes to optimization), and for satisfaction with life (Wave 2017) $(b=0.10, \mathrm{SE}=0.04, t=2.81, p=0.005)$, mediated by optimization (moderated path from optimization to well-being), being stronger for participants with low socioeconomic status.

\subsection{Discussion}

Study 2 aimed to replicate the results of Study 1 using a longitudinal design. The results showed that age stereotypes were positively associated with different kinds of well-being. Also, this association was partly mediated by engagement in self-regulation. The results show that the associations found in Study 1 using a cross-sectional design also occur in a longitudinal design and that they are unlikely to be caused by variations in state variables, such as current mood. In contrast to the results in Study 1, in which only optimization mediated the relationship between age stereotypes and well-being, we found a significant mediation for engagement across all three SOC strategies in Study 2. However, the strategies were measured with only one or two items in this study. Finally, the findings illustrate that age stereotypes and self-perception of ageing are related, but distinct concepts. Interestingly, the correlations increased for self-perceptions assessed at later points in time, that is, when participants reached an older age. Specifically, age stereotypes measured in 2008 correlated with self-perceptions of ageing in 2008 only at a level of $r=0.08, p<0.001$, but with self-perception of ageing assessed in 2014 at $r=0.18, p<0.001$ and in 2017 at $r=0.21, p<0.001$.

\section{General Discussion and Conclusion}

Age stereotypes are often regarded in a negative light and associated with discrimination (Nelson, 2005). However, this perspective neglects the fact that stereotypes can also be positive and directed towards the self. The present research was based on this reasoning. In particular, we argued that positive age stereotypes become very relevant for well-being as individuals grow older, because they motivate engagement in self-regulatory adaptation, which is crucial for successful aging. In line with this reasoning, we found consistent evidence in a cross-sectional and a longitudinal study that positive age stereotypes are associated with well-being and that this association is at least partially mediated via selfregulatory engagement. We observed this relationship by applying a broad measure of age stereotypes that referred to different life domains (Study 1) and a set of well-being measures taking the breadth of the well-being concept into account (Study 1 and 2). Moreover, Study 1 also revealed that the relationship between age stereotypes and well-being is 
not equally strong for all individuals, as it is reduced in people with a strong promotionfocused orientation.

The findings of the present studies are congruent with the theorizing of other researchers who proposed that age stereotypes are formed throughout life and become integrated into the self as the individual grows older (Kornadt \& Rothermund, 2011; Levy, 2003). By integrating age stereotypes into the self, processes are activated that lead to self-fulfilling prophecies (Levy, 2003; Wurm et al., 2013). Levy, Ashman, et al. (2000), Levy, Hausdorff, et al. (2000), for example, showed that positive age stereotypes strengthen the self-efficacy of individuals. However, the processes that drive these self-fulfilling prophecies are only partly understood. In particular, it was an open question whether more detailed processes of adaptation in goal pursuit are related to age stereotypes. The present research contributes to the understanding of these processes by revealing that the association between age stereotypes and well-being is mediated via self-regulatory engagement. However, the concrete mediations that we identified differed between Studies 1 and 2. In Study 2, we found a mediation of the association between age stereotypes and well-being for selection, compensation, and optimization. In contrast, Study 1 revealed a mediation mainly via optimization. At present, it is difficult to identify the concrete reason for this difference in the results of the studies. However, it is important to note that the measurement of SOC strategies was more elaborate in Study 1 compared to that in Study 2.

A possible explanation for the specific importance of optimization in Study 1 is that this self-regulatory strategy aims to maximize outcomes, whereas selection and compensation are loss-oriented strategies. Previous studies suggest that individuals with positive age stereotypes believe that they are able to achieve their goals (Levy, Ashman et al., 2000; Levy, Hausdorff et al., 2000), and that individuals with positive age stereotypes perceive themselves as less vulnerable to potential risks (Söllner \& Florack, 2019b). Hence, it is a plausible explanation that loss-oriented strategies do not increase in relevance for individuals holding positive age stereotypes who have very positive expectations regarding their future development. Indeed, this tendency for holding positive expectations is revealed in the positive correlation between age stereotypes and positive expectations in Study 1.

An inspection of the differential role of domain-specific age stereotypes revealed that stereotypes in the domain of leisure activities were the most important predictor for optimization. It is conceivable that positive age stereotypes in this domain motivate individuals to engage in leisure activities and that the level of activation spills over to optimization in other domains as well. Older adults differ very much in their leisure activities and participation in these activities might even increase when individuals retire (Janke et al., 2006). Hence, it is plausible that age stereotypes have the potential to contribute to older adults' participation in these activities.

In general, the relevance of domain-specific age stereotypes concerning engagement in domain-specific SOC strategies and well-being might be an interesting field for future research which could also offer insights into which domains of stereotypes might be relevant for interventions. The relevance of the differentiation between domains is also stressed by the direct link to well-being. For example, we observed in Study 1 that stereotypes in the domain of family and partnership and in the domain of leisure activities contributed uniquely to the prediction of affect balance, satisfaction with life and presence of meaning, while stereotypes in the domain of physical and mental fitness did not contribute uniquely to the prediction of these well-being measures.

Another interesting result of Study 1 is the moderating effect of promotion-focused self-regulation on the correlation between age stereotypes and well-being. This moderation is consistent with the argument that promotion-focused individuals construe their self 
(identity) more independently (Lee \& Aaker, 2004) than individuals with a weaker promotion-focused self-regulation. Stereotypes represent expectations prevailing in a society and should therefore be more relevant for individuals with an interdependent construction of the self. However, we did not find that age stereotypes exerted a stronger influence on well-being when prevention focus increased. One possible explanation for this low relevance of prevention focus is that it does not apply to positive age stereotypes and is more relevant when negative stereotypes are salient. At present, we cannot exclude the possibility that individuals with a prevention focus are more affected when stereotypes are more negative. In the sample of Study 1 , the stereotypes were rather positive $(M=3.54$, $S D=0.69$, scale range $1-5$ ), and it is obvious that participation in our survey required motivation and engagement. Hence, individuals with more negative age stereotypes may not have started or completed the survey. The same applies to participants in the representative survey of Study 2 where the mean value of the stereotype measure was above the scale midpoint $(M=2.60, S D=0.40$, scale range $1-4)$. The voluntary participation in the survey and potential selective sampling and/or dropout is an important limitation of the present research.

The present studies represent first steps to investigating the role of selection, optimization, and compensation as possible mediators of the association of age stereotypes with well-being. A strength of the present approach is that several aspects of well-being like satisfaction with life, affect, meaning, and search for meaning were assessed. However, while we assessed social aspects of age stereotypes, we did not assess social aspects of well-being like the satisfaction with social relationships. This is of course a shortcoming of the present research. But we would expect similar relationships of social well-being with age stereotypes as we identified for the other types of well-being, because social well-being has been found to correlate with aspects of well-being we assessed in the present studies (Kokko et al., 2013). A more important limitation of the current studies is that no intervention to shift the age stereotypes was conducted, which implies that no conclusions can be drawn regarding the causal direction of the observed associations. In this regard, it must also be pointed out as a limitation that the longitudinal study does not allow to rule out that the reported relationship between age stereotypes and relevant aspects of well-being might be affected by the influence of a third variable. Future research should further investigate whether age stereotypes have causal effects on self-regulatory strategies and well-being, and whether a shift in age stereotypes in a positive direction helps to increase engagement in adaptive self-regulatory strategies that are crucial for successful ageing and well-being.

Based on the reported findings on the relationship of age stereotypes with self-regulatory engagement, positive expectations, and well-being, the question arises as to how stereotypical views on age should now be dealt with. In our view, positive age stereotypes should be promoted both at societal levels, before people grow older, and at the individual level, when older adults are affected by self-perception of aging. Since individuals develop their self-perception of aging through the evaluation of their own aging processes and through the internalization of their expectations in the course of life into their image of a stereotypical old individual, which in the long run can act as a self-fulfilling prophecy, it seems to be of high relevance to initiate a realistic perception of aging with all its positive and negative facets at an early stage. A differentiated approach to the topic of aging at an early stage can thus be considered a sensitive preliminary stage that influences the later individual self-perception of aging. Therefore, developing interventions to combat ageism at the societal level is increasingly viewed as a critical component of healthy aging (World Health Organization, 2015). Common interventions include educating professionals and the general public (Klein et al., 2005), as well as fostering contact between older adults and 
young people (Chapman \& Neal, 1990), with a meta-analysis indicating that a combination of these interventions shows a promising effect of adopting positive stereotypes towards older adults (Burnes et al., 2019). Increased education to improve knowledge and understanding of what it means to become older seems to be an appropriate strategy to avoid inadequate stereotypical views and to promote positive attitudes and perception towards ageing (Donizzetti, 2019). Moreover, interventions could be tailored to older adults at an individual level. Levy et al. (2014), for example, demonstrated that implicit interventions have been shown to exert their influence on improved physical-functioning through one's acceptance of positive age-stereotypes. However, we are aware of the fact that stereotypes in general are not easily malleable. For example, the gender stereotypes observed over 30 years ago by Deaux and Lewis (1984) show a great deal of consistency with the types of gender stereotyping reported in the modern world (Haines et al., 2016). Such difficulties in changing stereotypes should alert us to identify sustainable ways to promote realistic age stereotypes in an attempt to observe the positive relation to well-being as reported in the current studies. In concert with findings about positive age stereotypes in specific domains (Kornadt \& Rothermund, 2011) and according to specific attributes (Gluth et al., 2010), the observed variance in age stereotypes in the current studies indicates that fostering positive age stereotypes is possible and can be achieved with a proper combination of interventions.

Acknowledgement We thank Annemijn Hofstede for her assistance and comments.

Author Contributions MD, and AF designed Study 1. MD collected the data for Study 1. MS, AF, and JKK wrote the manuscript. MS conducted the data analyses for Studies 1 and 2.

Funding Open access funding provided by University of Vienna. The present research did not receive funding.

Availability of the Data The research data of Study 1 will be available at the public institutional depository of the University of Vienna (https://uscholar.univie.ac.at/). For Study 2, we used data provided from the German Ageing Survey. The data is available for researchers at the Research Data Centre of the German Centre of Gerontology (DZA; www.german-ageing-survey.de).

\section{Declarations}

Conflict of interest The authors declare that they have no conflict of interest.

Ethical Standards Study 1 was conducted in accordance with the Declaration of Helsinki (revised 1983) and local guidelines of the Faculty of Psychology, University of Vienna. Participants were informed about the aim of the study and the confidentiality of the data collection, and they gave their consent to participate. Participants could also withdraw at any time during the studies. For Study 2, available data from the German Ageing Survey was used (www.german-ageing-survey.de).

Open Access This article is licensed under a Creative Commons Attribution 4.0 International License, which permits use, sharing, adaptation, distribution and reproduction in any medium or format, as long as you give appropriate credit to the original author(s) and the source, provide a link to the Creative Commons licence, and indicate if changes were made. The images or other third party material in this article are included in the article's Creative Commons licence, unless indicated otherwise in a credit line to the material. If material is not included in the article's Creative Commons licence and your intended use is not permitted by statutory regulation or exceeds the permitted use, you will need to obtain permission directly from the copyright holder. To view a copy of this licence, visit http://creativecommons.org/licenses/by/4.0/. 


\section{References}

Augoustinos, M., \& Walker, I. (1998). The construction of stereotypes within social psychology: From social cognition to ideology. Theory \& Psychology, 8(5), 629-652.

Baltes, P. B., \& Baltes, M. M. (1990). Psychological perspectives on successful aging: The model of selective optimization with compensation. Successful Aging: Perspectives from the Behavioral Sciences, 1(1), 1-34.

Baltes, P. B., Baltes, M. M., Freund, A. M., \& Lang, F. R. (1999). The measurement of selection, optimization, and compensation (SOC) by self report: Technical report. Berlin, Germany: Max Planck Institute for Human Development.

Burnes, D., Sheppard, C., Henderson, C. R., Wassel, M., Cope, R., Barber, C., \& Pillemer, K. (2019). Interventions to reduce ageism against older adults: a systematic review and meta-analysis. American Journal of Public Health, 109(8), 1-9.

Burr, A., Santo, J. B., \& Pushkar, D. (2011). Affective well-being in retirement: The influence of values, money, and health across three years. Journal of Happiness Studies, 12(1), 17-40.

Chapman, N. J., \& Neal, M. B. (1990). The effects of intergenerational experiences on adolescents and older adults. The Gerontologist, 30(6), 825-832.

Deaux, K., \& Lewis, L. L. (1984). Structure of gender stereotypes: Interrelationships among components and gender label. Journal of Personality and Social Psychology, 46(5), 991-1004.

Diekman, A. B., \& Hirnisey, L. (2007). The effect of context on the Silver ceiling: a role congruity perspective on prejudiced responses. Personality and Social Psychology Bulletin, 33(10), 1353-1366.

Diener, E., \& Chan, M. Y. (2011). Happy people live longer: Subjective well-being contributes to health and longevity. Applied Psychology: Health and Well-Being, 3(1), 1-43.

Diener, E. D., Emmons, R. A., Larsen, R. J., \& Griffin, S. (1985). The satisfaction with life scale. Journal of Personality Assessment, 49(1), 71-75.

Diener, E., Lucas, R. E., \& Oishi, S. (2002). Subjective well-being: The science of happiness and life satisfaction. In C. R. Snyder \& S. J. Lopez (Eds.), Handbook of Positive Psychology (pp. 63-73). Oxford University Press.

Diener, E., Suh, E. M., Lucas, R. E., \& Smith, H. L. (1999). Subjective well-being: Three decades of progress. Psychological Bulletin, 125(2), 276-302.

Diener, E., Wirtz, D., Tov, W., Kim-Prieto, C., Choi, D. W., Oishi, S., \& Biswas-Diener, R. (2010). New well-being measures: Short scales to assess flourishing and positive and negative feelings. Social Indicators Research, 97(2), 143-156.

Donizzetti, A. R. (2019). Ageism in an aging society: The role of knowledge, anxiety about aging, and stereotypes in young people and adults. International Journal of Environmental Research and Public Health, 16(8), 1329-1339.

Fiske, S. T., Cuddy, A. J. C., \& Glick, P. (2007). Universal dimensions of social cognition: Warmth and competence. Trends in Cognitive Sciences, 11(2), 77-83.

Florack, A., Friese, M., \& Scarabis, M. (2010). Regulatory focus and reliance on implicit preferences in consumption contexts. Journal of Consumer Psychology, 20, 193-204.

Florack, A., Keller, J., \& Palcu, J. (2013a). Regulatory focus in economic contexts. Journal of Economic Psychology, 38, 127-137.

Florack, A., Palcu, J., \& Friese, M. (2013b). The moderating role of social modeling in food intake. Appetite, 69, 114-122.

Florack, A., Scarabis, M., \& Gosejohann, S. (2005). Regulatory focus and consumer information processing. In F. R. Kardes, P. M. Herr, \& J. Nantel (Eds.), Applying social cognition to consumer-focused strategy (pp. 235-263). Erlbaum.

Freund, A. M. (2008). Successful aging as management of resources: The role of selection, optimization, and compensation. Research in Human Development, 5(2), 94-106.

Freund, A. M., \& Baltes, P. B. (1998). Selection, optimization, and compensation as strategies of life management: correlations with subjective indicators of successful aging. Psychology and Aging, 13(4), 531-543.

Freund, A. M., \& Baltes, P. B. (1999). Selection, optimization, and compensation as strategies of life management. Psychology and Aging, 14(4), 700-702.

Freund, A. M., \& Baltes, P. B. (2002). Life-management strategies of selection, optimization and compensation: Measurement by self-report and construct validity. Journal of Personality and Social Psychology, 82(4), 642-662.

Gaillard, M., Desmette, D., \& Keller, J. (2011). Regulatory focus moderates the influence of age-related stereotypic expectancies on older adults' test performance and threat-based concerns. European Review of Applied Psychology, 61(1), 23-29. 
Glaesmer, H., Hoyer, J., Klotsche, J., \& Herzberg, P. Y. (2008). Die deutsche Version des Life-OrientationTests (LOT-R) zum dispositionellen Optimismus und Pessimismus. Zeitschrift Für Gesundheitspsychologie, 16(1), 26-31.

Glaesmer, H., Grande, G., Braehler, E., \& Roth, M. (2011). The German version of the satisfaction with life scale (SWLS). European Journal of Psychological Assessment, 27(2), 127-132.

Gluth, S., Ebner, N. C., \& Schmiedek, F. (2010). Attitudes toward younger and older adults: The German aging semantic differential. International Journal of Behavioral Development, 34(2), 147-158.

Grant, H., \& Higgins, E. T. (2003). Optimism, promotion pride, and prevention pride as predictors of quality of life. Personality and Social Psychology Bulletin, 29(12), 1521-1532.

Haines, E. L., Deaux, K., \& Lofaro, N. (2016). The Times they are a-changing ... or are they not? A comparison of gender stereotypes, 1983-2014. Psychology of Women Quarterly, 40(3), 353-363.

Hayes, A. F. (2012). Process [SPSS Macro]. Retrieved from, http://afhayes.com/introduction-to-media tion-moderation-andconditional-process-analysis.html.

Higgins, E. T. (1997). Beyond pleasure and pain. American Psychologist, 52(12), 1280-1300.

Higgins, E. T. (1998). Promotion and prevention: Regulatory focus as a motivational principle. In M. P. Zanna (Ed.), Advances in Experimental Social Psychology (Vol. 30, pp. 1-46). San Diego, CA: Academic Press.

Higgins, E. T., Friedman, R. S., Harlow, R. E., Idson, L. C., Ayduk, O. N., \& Taylor, A. (2001). Achievement orientations from subjective histories of success: Promotion pride versus prevention pride. European Journal of Social Psychology, 31(1), 3-23.

Hummert, M. L. (1999). A social cognitive perspective on age stereotypes. In T. M. Hess \& F. Blanchard-Fields (Eds.), Social cognition and aging (pp. 175-196). Academic Press.

Hummert, M. L., Garstka, T. A., Shaner, J. L., \& Strahm, S. (1994). Stereotypes of the elderly held by young, middle-aged, and elderly adults. Journal of Gerontology, 49(5), 240-249.

Janke, M., Davey, A., \& Kleiber, D. (2006). Modeling change in older adults' leisure activities. Leisure Sciences, 28(3), 285-303.

Jopp, D., \& Smith, J. (2006). Resources and life-management strategies as determinants of successful aging: On the protective effect of selection, optimization, and compensation. Psychology and Aging, 21(2), 253-265.

Keller, J., \& Bless, H. (2008). When positive and negative expectancies disrupt performance: Regulatory focus as a catalyst. European Journal of Social Psychology, 38(2), 187-212.

Kite, M. E., Stockdale, G. D., Whitley, E. B., \& Johnson, B. T. (2005). Attitudes toward younger and older adults: an updated meta-analytic review. Journal of Social Issues, 61(2), 241-266.

Klein, D. A., Council, K. J., \& McGuire, S. L. (2005). Education to promote positive attitudes about aging. Educational Gerontology, 31(8), 591-601.

Kokko, K., Korkalainen, A., Lyyra, A.-L., \& Feldt, T. (2013). Structure and continuity of well-being in mid-adulthood: A longitudinal study. Journal of Happiness Studies, 14(1), 99-114.

Kornadt, A. E., \& Rothermund, K. (2011). Contexts of aging: Assessing evaluative age stereotypes in different life domains. Journals of Gerontology Series b: Psychological Sciences and Social Sciences, 66(5), 547-556.

Kotter-Grühn, D., \& Hess, T. M. (2012). The impact of age stereotypes on self-perceptions of aging across the adult lifespan. The Journals of Gerontology: Series B, 67(5), 563-571.

Lacey, H. P., Smith, D. M., \& Ubel, P. A. (2006). Hope I die before I get old: Mispredicting happiness across the adult lifespan. Journal of Happiness Studies, 7(2), 167-182.

Lawton, M. P. (1975). The Philadelphia geriatric center morale scale: A revision. Journal of Gerontology, 30(1), 85-89.

Leder, S., Florack, A., \& Keller, J. (2013). Thoughts about possible failure: regulatory focus and the anticipation of regret. Social Cognition, 31, 349-373.

Leder, S., Florack, A., \& Keller, J. (2015). Self-regulation and protective health behavior: How regulatory focus and anticipated regret are related to vaccination decisions. Psychology and Health, 30(2), 165-188.

Lee, A. Y., \& Aaker, J. L. (2004). Bringing the frame into focus: The influence of regulatory fit on processing fluency and persuasion. Journal of Personality and Social Psychology, 86(2), 205-218.

Levy, B. R. (2003). Mind matters: Cognitive and physical effects of aging self-stereotypes. The Journals of Gerontology Series b: Psychological Sciences and Social Sciences, 58(4), 203-211.

Levy, B. R. (2009). Stereotype embodiment: A psychosocial approach to aging. Current Directions in Psychological Science, 18(6), 332-336.

Levy, B., Ashman, O., \& Dror, I. (2000a). To be or not to be: The effects of aging stereotypes on the will to live. OMEGA-Journal of Death and Dying, 40(3), 409-420. 
Levy, B. R., Hausdorff, J. M., Hencke, R., \& Wei, J. Y. (2000b). Reducing cardiovascular stress with positive self-stereotypes of aging. The Journals of Gerontology Series b: Psychological Sciences and Social Sciences, 55(4), 205-213.

Levy, B. R., \& Leifheit-Limson, E. (2009). The stereotype-matching effect: Greater influence on functioning when age stereotypes correspond to outcomes. Psychology and Aging, 24(1), 230-233.

Levy, B. R., Pilver, C., Chung, P. H., \& Slade, M. D. (2014). Subliminal strengthening: Improving older individuals' physical function over time with an implicit-age-stereotype intervention. Psychological Science, 25(12), 2127-2135.

Levy, B. R., Slade, M. D., Kunkel, S. R., \& Kasl, S. V. (2002). Longevity increased by positive selfperceptions of aging. Journal of Personality and Social Psychology, 83(2), 261-270.

Levy, B. R., Slade, M. D., May, J., \& Caracciolo, E. A. (2006). Physical recovery after acute myocardial infarction: positive age self-stereotypes as a resource. The International Journal of Aging and Human Development, 62(4), 285-301.

MacLeod, A. K., Coates, E., \& Hetherton, J. (2008). Increasing well-being through teaching goal-setting and planning skills: Results of a brief intervention. Journal of Happiness Studies, 9(2), 185-196.

Mock, S. E., \& Eibach, R. P. (2011). Aging attitudes moderate the effect of subjective age on psychological well-being: Evidence from a 10-year longitudinal study. Psychology and Aging, 26(4), 979-986.

Nelson, T. D. (2005). Ageism: Prejudice against our feared future self. Journal of Social Issues, 61(2), 207-221.

$\mathrm{Ng}$, E. S., \& Law, A. (2014). Keeping up! Older workers' adaptation in the workplace after age 55. Canadian Journal on Aging/la Revue Canadienne Du Vieillissement, 33(1), 1-14.

Perry, E. L., \& Finkelstein, L. M. (1999). Toward a broader view of age discrimination in employmentrelated decisions: a joint consideration of organizational factors and cognitive processes. Human Resource Management Review, 9(1), 21-49.

Pinquart, M. (2002). Good news about the effects of bad old-age stereotypes. Experimental Aging Research, 28(3), 317-336.

Reker, G. T., \& Wong, P. T. P. (1988). Aging as an individual process: Toward a theory of personal meaning. In J. E. Birren \& V. L. Bengtson (Eds.), Emergent theories of aging (pp. 214-246). New York: Springer Publishing Company.

Rothermund, K. (2005). Effects of age stereotypes on self-views and adaptation. In W. Greve, K. Rothermund, \& D. Wentura (Eds.), The adaptive self: personal continuity and intentional self-development (pp. 223-242). Hogrefe Huber Publishers.

Sarkisian, C. A., Prohaska, T. R., Wong, M. D., Hirsch, S., \& Mangione, C. M. (2005). The relationship between expectations for aging and physical activity among older adults. Journal of General Internal Medicine, 20(10), 911-915.

Scheier, M. F., Carver, C. S., \& Bridges, M. W. (1994). Distinguishing optimism from neuroticism (and trait anxiety, self-mastery, and self-esteem): A reevaluation of the Life Orientation Test. Journal of Personality and Social Psychology, 67(6), 1063-1078.

Shapiro, J. R., \& Neuberg, S. L. (2007). From stereotype threat to stereotype threats: Implications of a multi-threat framework for causes, moderators, mediators, consequences, and interventions. Personality and Social Psychology Review, 11(2), 107-130.

Shenkman, G., Ifrah, K., \& Shmotkin, D. (2018). The association between negative attitudes toward aging and mental health among middle-aged and older gay and heterosexual men in Israel. Aging \& Mental Health, 22(4), 503-511.

Söllner, M., \& Florack, A. (2019a). Who provides feedback to older drivers when driving ability tails off: The role of age stereotypes. Transportation Research Part f: Traffic Psychology and Behaviour, 60, 217-227.

Söllner, M., \& Florack, A. (2019b). Age stereotypes and compliance with feedback in elderly drivers. Transportation Research Part f: Traffic Psychology and Behaviour, 67, 66-77.

Steger, M. F., Frazier, P., Oishi, S., \& Kaler, M. (2006). The meaning in life questionnaire: Assessing the presence of and search for meaning in life. Journal of Counseling Psychology, 53(1), 80-93.

Tovel, H., \& Carmel, S. (2014). Maintaining successful aging: The role of coping patterns and resources. Journal of Happiness Studies, 15(2), 255-270.

Ward, R. A. (1977). The impact of subjective age and stigma on older persons. Journal of Gerontology, 32(2), 227-232.

Watson, D., Clark, L. A., \& Tellegen, A. (1988). Development and validation of brief measures of positive and negative affect: the PANAS scales. Journal of Personality and Social Psychology, 54(6), 1063-1070.

Wiese, B. S., Freund, A. M., \& Baltes, P. B. (2000). Selection, optimization, and compensation: An actionrelated approach to work and partnership. Journal of Vocational Behavior, 57(3), 273-300. 
World Health Organization (WHO). (2015). World Report on Ageing and Health. Geneva: WHO.

Wurm, S., Warner, L. M., Ziegelmann, J. P., Wolff, J. K., \& Schütz, B. (2013). How do negative self-perceptions of aging become a self-fulfilling prophecy? Psychology and Aging, 28(4), 1088-1097.

Publisher's Note Springer Nature remains neutral with regard to jurisdictional claims in published maps and institutional affiliations. 